\title{
Predictores tempranos de la recuperación luego de un traumatismo craneal leve
}

\author{
Early predictors of recovery after mild traumatic brain injury
}

\section{Comentado de:}

van der Naalt J, et al. Early predictors of outcome after mild traumatic brain injury (UPFRONT): an observational cohort study. Lancet Neurol 2017; 16(7): 532-40 ${ }^{1}$.

\section{Objetivo}

Identificar los factores pronósticos que inciden en la recuperación posterior al traumatismo encéfalo craneal (TEC) leve.

\section{Diseño, lugar y pacientes}

Cohorte prospectiva estudiada en Holanda. Participaron, entre 2013 y 2015, 910 adultos afectados de un TEC leve (escala de Glasgow de 13 a 15 puntos) con amnesia post-traumática menor de 24 horas o pérdida de conocimiento menor a 30 minutos.

\section{Evaluación de factores pronósticos}

Al momento de admisión se evaluó: severidad del traumatismo (escala de Glasgow y alteraciones en la tomografía axial computada de cerebro), datos demográficos (edad, género, nivel educativo, estado mental pre-lesión y lesiones cerebrales previas) y condiciones físicas (uso de alcohol el día del traumatismo, dolor de cuello, cefalea, náuseas y mareos).

A las dos semanas se recolectaron datos sobre el estado anímico (Escala Hospitalaria de Ansiedad y Depresión), impacto emocional (Escala de Impacto del Evento), capacidad de afrontamiento de situaciones adversas (Lista de Afrontamiento Utrecht) y quejas post-traumatismo.

El resultado principal consistió en la recuperación funcional a los seis meses utilizando la Escala de Glasgow de Recuperación Extendida (por sus siglas en inglés, GOSE), cuyo resultado se dicotomizó en recuperación completa (GOSE $=8$ ) o incompleta (GOSE < 8).

\section{Resultados principales}

A las dos semanas, el $84 \%$ de los participantes presentaba una o más quejas (principalmente nauseas, cefaleas y fatiga), lo cual correlacionó positivamente con ansiedad ( $r=0,42 ; p<0,0001)$, depresión $(r=0,52 ; p<0,0001)$ y estrés post-traumático $(r=0,52$; $p<0,0001)$.

A los seis meses, 671 pacientes continuaron en la cohorte, de los cuales el $72 \%$ presentaron una o más quejas. El $44 \%$ de los pacientes tuvo recuperación incompleta.

Se desarrollaron dos modelos de regresión logística: al momento de la admisión, y a las dos semanas. El primer modelo identificó que a mayor nivel educativo, sexo masculino, ausencia de enfermedad mental, presencia de intoxicación por alcohol, ausencia de dolor de cuello, mayores valores en la escala de Glasgow, y mayor duración de la amnesia post-traumática, hubo mayor probabilidad de recuperación completa. El segundo modelo, por su parte, mostró que ante la ausencia de depresión, menor nivel de queja, menor puntuación en personalidad pasiva, mayor puntaje en ansiedad y en personalidad evitativa, hubo también mayor probablilidad de recuperación.

A partir de este análisis se identificaron varios factores predictores de recuperación a los seis meses, incluyendo el nivel educativo y la edad (área bajo la curva $=0,72$ ), con una clara mejoría de predicción al incluir los valores de distress emocional y capacidad de afrontamiento de situaciones adversas a las dos semanas (área bajo la curva $=0,79$ ).

\section{Conclusiones}

La evaluación de factores psicológicos (como el distress emocional y la incapacidad de afrontamiento de situaciones adversas al poco tiempo de ocurrida la lesión), conjuntamente con problemas mentales pre-traumatismo, nivel educativo y edad, son factores importantes para predecir la recuperación a los seis meses del traumatismo craneal leve. Esto permitiría identificar un subgrupo de pacientes en riesgo de evolucionar con recuperación incompleta para diseñar una intervención temprana que mejore su pronóstico.

\section{Fuente de financiamiento}

Dutch Brain Foundation.

\section{Comentario}

El 80 a $90 \%$ de los traumatismos craneales son categorizados como leves, y de éstos, el $30 \%$ de los individuos afectados no retorna a su trabajo o actividad previa luego de seis meses del evento. Sin embargo, estos no presentan alteraciones en las neuroimágenes, y las evaluaciones neurocognitivas retornan a valores normales en el largo plazo.

Previamente se identificó a la edad y el nivel educativo como factores pronósticos de recuperación ${ }^{2-4}$; manteniéndose en el debate si las quejas persistentes son consecuencia de una lesión cerebral, factores psicológicos o bien, una combinación de ambos.

La presencia de uno o más factores de distress emocional se relacionan con mayores quejas post-traumatismo y con una recuperación incompleta ${ }^{4}$. Según estudios previos, el tipo específico de distress emocional (ansiedad, depresión y/o estrés post-traumático) no fue relevante en la persistencia de la queja. Sin embargo, la capacidad del paciente de afrontar situaciones adversas (en este trabajo evaluado por la Lista de Afrontamiento Utrecht) fue la característica más importante.

Diversos estudios han sugerido que una intervención psicológica podría ser efectiva en prevenir el desarrollo y persistencia de las quejas post-traumáticas ${ }^{5-7}$.

Teniendo en cuenta lo anterior, la pesquisa del impacto emocional luego del TEC leve es uno de los factores más importantes para identificar aquellos individuos en riesgo de una recuperación incompleta. Esto permitiría identificar un grupo de pacientes que pueda ser objeto de intervención precoz para mejorar su evolución. Futuros trabajos determinarán cuál sería la intervención más beneficiosa. 
Dentro de las limitaciones del estudio, es importante enunciar que a los seis meses del seguimiento se perdieron pacientes significativamente más jóvenes. Es probable, además, que los pacientes perdidos sean aquellos con mejor recuperación, y posiblemente con un menor incentivo para participar a más largo plazo en el estudio.

Nuria Elide Cámpora [ Sección Trastornos de la Memoria y la Conducta, Servicio de Neurología, Hospital Italiano de Buenos Aires nuria.campora@ hospitalitaliano.org.ar ]

Campora NE. Predictores tempranos de la recuperación luego de un traumatismo craneal leve. Evid Actual Pract Ambul. 2019;22(02):e001111. Comentado de: van der Naalt J, et al. Early predictors of outcome after mild traumatic brain injury (UPFRONT): an observational cohort study. Lancet Neurol 2017; 16(7): 532-40. PMID: 28653646.

\section{Referencias}

1. van der Naalt $\mathrm{J}$, et al. Early predictors of outcome after mild traumatic brain injury (UPFRONT): an observational cohort study. Lancet Neurol. 2017;16(7):532-540. Available from: 10.1016/S1474-4422(17)30117-5.

2. Ponsford J, et al. Factors influencing outcome following mild traumatic brain injury in adults. J Int Neuropsychol Soc. 2000;65(5):568-79.

3. Jacobs $\mathrm{B}$, et al. Outcome prediction in mild traumatic brain injury: age and clinical variables are stronger predictors than $\mathrm{CT}$ abnormalities. $\mathrm{J}$ Neurotrauma. 2010;27(4):655-68. Available from: 10.1089/neu.2009.1059.

4. Hou R, et al. When a minor head injury results in induring symptoms: a prospective investigation of risk factors for postconcussional syndrome after mild traumatic brain injury. J Neurol Neurosurg Psych. 2012;83(2):217-23. Available from: 10.1136/jnnp-2011-300767.

5. Bell KR, et al. The efect of telephone counselling on reducing post-traumatic symptoms after mild traumatic brain injury: a randomised trial. J Neurol Neurosurg Psychiatry. 2008;79(11):2751-81. Available from: 10.1136/jnnp.2007.141762.

6. Al-Sayegh A, et al. Psychological approaches to treatment of post concussion syndrome: a systematic review. J Neurol Neurosurg Psychiatry. 2010;81(10):1281-34. Available from: 10.1136/jnnp.2008.170092.

7. Silverberg ND, et al. Cognitive-behavioral prevention of postconcussion syndrome in at-risk patients: a pilot randomized controlled trial. J Head Trauma Rehabil. 2013;28(4):313-22. Available from: 10.1097/HTR.0b013e3182915cb5. 